A section of the tumour shows spaces or "cysts" of the following three types:-

(1) Lumina of tubules lined by columnar epithelium similar to that of the normal sweat gland, and having sometimes also an outer layer of cubical cells with oval nuclei which probably represent the myoepithelial cells of the normal gland.

(2) Lumina lined by smaller altered gland cells having denser nuclei.

(3) Cystic spaces due to breakdown of tissue cells, lined by partly degenerated polyhedral cells or in places merely walled by the stroma, and containing an albuminous coagulum and occasionally disintegrating parenchymal cells.

\title{
Summary
}

A case of adenoma of a sweat gland has been described and it is suggested that if consideration be given to the long history, the presence of the crust, the mobility of the skin over the edges of the tumour, the translucency, and the'firm consistency, perhaps best tested with the blunt end of a probe for cystic spaces, a clinical diagnosis of this condition should be possible.

\section{AN UNUSUAL CASE OF SYMMETRICAL, BILATERAL, NON-TRAUMATIC IRIS PROLAPSE.}

B Y

\author{
M. L. NaIRAC \\ MAURITIUS
}

A NEGRO woman aged 22 years, was transferred from the island of Rodriguez to the Civil Hospital, Port Louis, Mauritius, on March 29, 1947.

I here quote the report of the Government Medical Officer who first saw the case.

"Two weeks before she was seen, on March 15, she felt a strong, burning pain in the right eye followed by a discharge of 'pus.' The following day the left eye became similarly affected. The pain was such that the patient could not open her eyes and in her own words was blind for a few days."

"When first seen the patient was suftering from intense photophobia. Both eyes were found to have a staphyloma in the upper quadrant, the right side greater than the left. The pupils were irregular and drawn up. The walls of the herniation were so thin

\footnotetext{
* Received for publication, May 26, 1947.
} 
that they threatened to rupture. They were transparent, however, and showed no signs of injury or inflammation."

"She was married 5 years ago and has three children; no miscarriages."

"She was transferred to Mauritius on March 27, 1947."

I saw the patient on April 1, 1947, and found the following condition :-

Both eyes had an iris prolapse between 11 o'clock and 1 o'clock, through gaps which measured $6 \mathrm{~mm}$. by $4 \mathrm{~mm}$. in the right eye and $6 \mathrm{~mm}$. by $3 \mathrm{~mm}$. in the left eye. The upper parts of the irides were well prolapsed through the openings and formed bulges: in

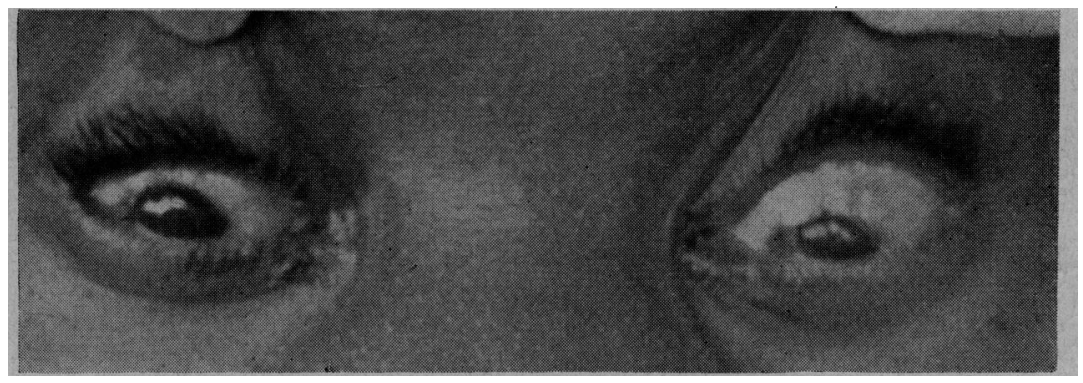

FIG. 1 .

the right eye $6 \mathrm{~mm} . \times 4 \mathrm{~mm} . \times 3 \mathrm{~mm}$. and in the left eye $6 \mathrm{~mm} . \times 3 \mathrm{~mm}$. $\times 3 \mathrm{~mm}$. The pupils were drawn up towards the perforation more so in the right eye than in the left, but the edge of either pupil was not involved in the prolapse. The hole in each cornea was clearcut, oval, anit placed just central to the corneo-scleral junction. There were no signs of inflammation not even some ciliary injection near the prolapsed part of the iris. The rest of the cornea was bright and clear. The iris was normal in other respects; there were no posterior synechiae and its colour was normal. The anterior chamber below the prolapse was well-formed and the aqueous was clear. The fundi could be well-seen and were normal. There was no cupping of the discs.

Fig. 1 shows the condition, and although the photograph is not perfect it shows well the two bulges of the prolapsed irides, and the lack of inflammation. Kahn reaction was negative and there was no history of trauma. There was no evidence of avitaminosis. Atropine was instilled and the pupils dilated very well.

\section{Treatment}

It seemed obvious that it would be too great a gap to close with a conjunctival flap if the prolapsed part of the iris was abscised. 
It was therefore resolved not to excise iris tissue but instead to cauterize it with the electric cautery along the whole of the prolapsed part and along the edge of the corneal hole, and then to apply a thick conjunctival flap which would thus adhere more readily.

On April 8, 1947, the left eye was done and the operation was carried out as planned.

On April 15, 1947, the flap having taken well, in the left eye, the other eye was similarly treated. But this time the iris was so thin that on the first impact of a not very hot cautery perforation occurred. We did not allow this to disturb the operation which was.

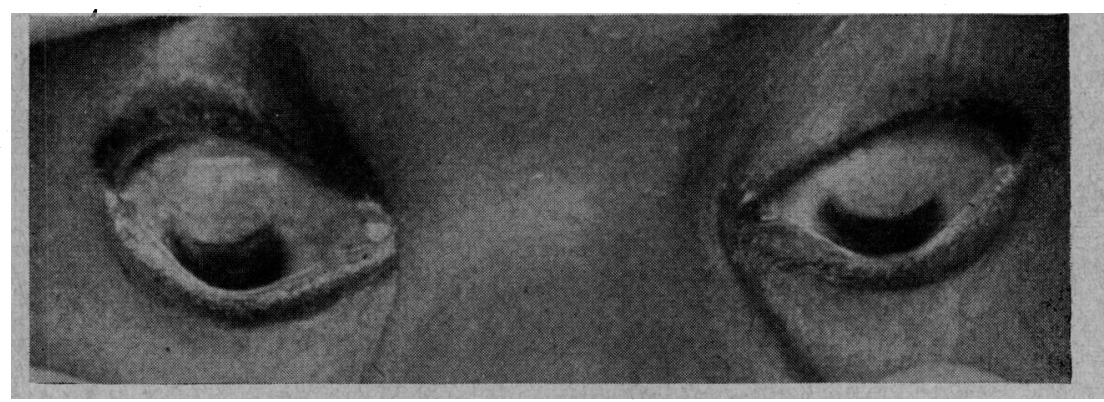

FIG. 2.

carried out again as planned. The result was better than in the left eye.

Fig. 2 shows the condition after operation. This was taken on April 22, 1947.

On April 30, 1947, the patient was allowed out of hospital, and as far as one can tell has excellent sight and a strong conjunctival "patch" on either eye which should last her a long time.

The interesting problem here is one of aetiology. The probable explanation is of a bilateral acute infection, with the formation of corneal ulcers, which with the help of severe blepharospasm and probably a fair amount of rubbing perforated quickly and healed.

I do not think one can explain the condition in any other way. "Trophic" changes, avitaminosis, etc., would have shown other signs in the cornea and conjunctiva. These were lacking completely, nor was there any evidence of trauma. The curious thing is the symmetry of the lesions.

I would be glad to hear of any other similar case, or of any publication on the subject.

I am indebted to Dr. M. Shun-Shin, who first saw the case and brought it over Mauritius. 